\section{Apuntes sobre las relaciones entre el Movimiento de Izquierda \\ Revolucionaria y el Partido Comunista de Chile.}

\author{
Caridad Massón Sena*
}

El Partido Obrero Socialista de Chile fundado por Luis Emilio Recabarren se adhirió a la Internacional Comunista (IC) en 1921 y, al año siguiente se convirtió en Partido Comunista. Según un informe de M. A. Komin, representante de la Comintern en América del Sur, el movimiento obrero en Chile era muy unido, tenía un carácter más proletario que en otros países de la región y, al mismo tiempo, varios representantes en el Parlamento. ${ }^{1}$ Su línea política se basó en la conquista del poder no por medios insurrecciónales, sino a través de las instituciones democráticas burguesas

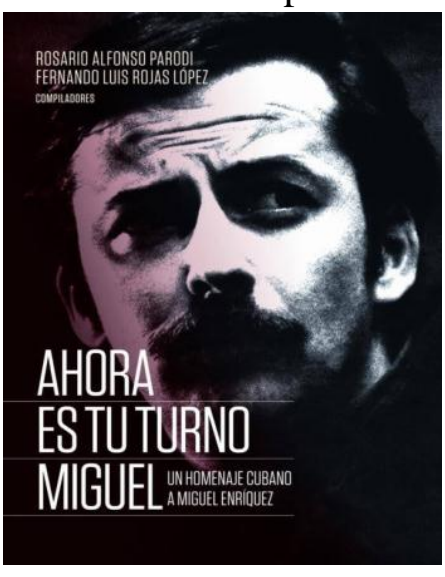

embargo se convirtió en un actor político con gran arraigo entre los mineros y otros sectores proletarios. Esta es la etapa en que comienza una relación más directa con la IC. En ese contexto de clandestinidad, el Comité Central del PCCh se dividió ante la ambigüedad de aquel gobierno que se movía entre las posiciones anticomunistas y los propósitos de modernización económica, desarrollo nacional y medidas a favor de las capas más pobres. Algunos de sus miembros pensaban que el gobierno tenía un carácter fascista y había que luchar contra él, mientras que otros querían apoyar el proyecto corporativista del presidente. Por su parte, el Secretariado fundamentalmente. Es por ello que en 1924, se involucró seriamente en la campaña electoral. $^{2}$

Durante los años de la dictadura de Carlos Ibáñez (1927-1931), el Partido vivió un período de gran represión, sin

\footnotetext{
* Investigadora del Instituto Cubano de Cultura Juan Marinello

1 Olga Ulianova, «Primeros contactos entre el Partido Comunista de Chile y Comintern: 19221927», en Olga Ulianova y Alfredo Riquelme Segovia (eds.), Chile en los archivos soviéticos 1922-1991, t. 1, Santiago de Chile, LOM Ediciones, 2005, p. 98.

2 Eugenia Palieraki, ¡La revolución ya viene! El MIR chileno en los años 1960, Santiago, LOM Ediciones, 2014, p.12.
}

combatir solos contra él? Rosas creía imposible que, en esos momentos, se pudiera establecer un gobierno obrero y campesino, por eso sugirió apoyar a la burguesía y enarbolar un plan de demandas populares inmediatas. La IC no dio mucha importancia a lo que pasaba en Chile entonces. ${ }^{3}$

\footnotetext{
3 Olga Ulianova, «El PC Chileno durante la dictadura de Ibañez (1927-1931): primera clandestinidad y"bolchevización" estaliniana», en Olga Ulianova y Alfredo Riquelme Segovia (eds.), Chile en los archivos soviéticos 19221991, t. 1, Santiago de Chile, LOM Ediciones, 2005, pp. 215-232.
} 
Entre 1928 y 1929, la mayoría de la dirección del Partido estaba en prisión, sus filas desmembradas y con múltiples contradicciones internas. Sin embargo, en 1929 empezó a implementarse la "bolchevización"4 encauzada directamente desde el SSA por el comunista italo-argentino Vittorio Codovilla, quien pretendió llevar la dirección del Partido hacia Valparaíso, donde se encontraba el grupo liderado por Galo González. En esa etapa, se daban fuertes contradicciones entre Codovilla, representante además de la táctica "clase contra clase", y el grupo residente en Santiago, dirigido por Manuel Hidalgo, el cual era favorable a realizar asociaciones con otros sectores políticos. Esta situación fue muy discutida y Codovilla desautorizó las intenciones de crear un partido legal y a las posiciones hidalguistas, asunto que terminó con la intervención directa del SSA y las expulsiones de militantes y dirigentes. $^{6}$

Durante el período que va de la caída de Ibáñez a la formación del Frente

\footnotetext{
${ }^{4}$ La bolchevización fue una directiva de la IC que en término generales, indicaba a los PPCC que debían adquirir un carácter de masas a través de su reestructuración por medio de células dentro de las empresas, del impulso a la labor en los sindicatos obreros y entre el campesinado. En cuanto a la organización interna, esta debía basarse en un fuerte centralismo y una severa disciplina.

5 La política de "clase contra clase" prohibía alianzas con grupos de otras tendencias ideológicas $\mathrm{y}$ el trabajo dentro de los sindicatos reformistas y en los parlamentos burgueses. El frente único solo se podría concertar con elementos de la base de las organizaciones sindicales y partidistas.

6 Olga Ulianova, «El PC Chileno durante la dictadura de Ibáñez (1927-1931): primera clandestinidad y "bolchevización" estaliniana», en Olga Ulianova y Alfredo Riquelme Segovia (eds.), Chile en los archivos soviéticos 1922-1991, t. 1, Santiago de Chile, LOM Ediciones, 2005, pp. 233258.
}

Popular en 1936, el Partido osciló entre las actitudes muy radicales y la política de colaboración de clases, a la par que sufrió una grave crisis interna con la escisión de un sector afín al trotskismo.

Al gestarse el golpe de Estado de 1932 y la proclamación de una República Socialista, la dirigencia comunista trató de instaurar una dictadura del proletariado basada en los soviets. Ello sembró mucha confusión en su militancia. Posteriormente en julio de 1933 dio un giro importante al pasar a otra estrategia basada en la revolución democrática burguesa, agraria y antiimperialista, que facilitaba alianzas de con otras clases y frentes amplios. Pasó a considerar a la burguesía nacional como el principal aliado del proletariado, cuya tarea iba a ser el desarrollo del capitalismo. Lucharían juntos contra tres enemigos esenciales: el imperialismo estadounidense, el latifundio y la oligarquía nacional. Se adoptaba así una línea más moderada, alejándose del izquierdismo y el sectarismo.

La política de Frente Popular, adoptada por el VII Congreso de la IC en 1935, ya era conocida en Chile y su aplicación tenía por objetivo impedir el desarrollo del fascismo; frenar la fuerza de la derecha; unir a la clase obrera con las clases medias; impulsar la liberación nacional, la industrialización y la modernización del país. Ella permitió crear una coalición que eligió como presidente al político del Partido Radical, Pedro Aguirre Cerda, en 1938, quien organizó su gabinete acompañado de socialistas y democráticos, pero exceptuando a los comunistas.

Aquella táctica frentepopulista resultó positiva en lo inmediato. El PC logró aumentar sus votos parlamentarios y hasta el nombramiento de tres ministros 
más adelante. A largo plazo quedaron beneficios en los sectores de educación y salud y la experiencia de aquel esfuerzo democrático. Sin embargo, la guerra fría impuso un realineamiento gubernamental contra los comunistas. Estos fueron desalojados del gobierno y su organización declarada ilegal por la Ley de Defensa Permanente de la Democracia en septiembre de 1948.

En las circunstancias descritas se produjo un repliegue combativo y se formaron dos tendencias en el seno partidista: una minoritaria sostenida por Luis Reinoso orientada a la lucha armada, cuyo el objetivo era implantar una democracia popular; $\mathrm{y}$ otra mayoritaria sostenida por el Secretario General, Galo González, que impulsaba un Programa de Emergencia para poder unificar las fuerzas de oposición y realizar la revolución democráticaburguesa. Las desavenencias entre González y Reinoso acabaron resolviéndose con la expulsión de este último. ${ }^{7}$

Ante la proximidad las elecciones presidenciales de 1952, muchas organizaciones y dirigentes políticos trataron de buscar apoyo del PC para los comicios. En su novena Conferencia, este adoptó la línea de Frente de Liberación Nacional, la tesis de un gobierno de coalición amplia, capaz de llevar adelante la revolución democrático-burguesa. La misma tenía similitudes con las anteriores, pero entre sus especificidades estaba la pretensión de alianzas con

\footnotetext{
7 Manuel Loyola T., «"Los destructores del Partido": notas sobre el reinosismo en el Partido Comunista de Chile», Revista Izquierdas, a. 1, n.2, en

http://www.izquierdas.cl/images/pdf/2011/07/Rei nosismo.pdf, consultado diciembre de 2014.
}

algunos sectores de la burguesía, pero con hegemonía obrera y la adopción de la vía pacífica como medio para hacer las transformaciones. El XX Congreso del Partido Comunista de la Unión Soviética aprobó a nivel internacional dicha política.

Según Luis Corvalán, secretario general del Partido, la vía pacífica no estaba necesariamente vinculada a las elecciones, era una lucha de masas para acceder pacíficamente al poder de distintas maneras. Una de ellas podría ser la elección del Presidente de la República. Además la misma no excluía totalmente las acciones violentas. ${ }^{8}$ Los comunistas consideraban que la contradicción principal en la sociedad chilena se reflejaba en dos bloques: el pueblo que incluía prácticamente a toda la sociedad y el poder económico y estatal, o sea, los latifundistas y la burguesía monopólica. Consideraban ineludibles la modernización y democratización para llegar al socialismo a través de la democracia. Esa política fue revalidada en 1962 y, a la derrota del socialista Salvador Allende en las elecciones de 1964, el PC de Chile inició la ampliación de sus coaliciones para los próximos sufragios.

El tema de la vía pacífica se situó en el centro de la polémica en los años 60. En América Latina tuvo además sus peculiaridades por las influencias de la Revolución Cubana, la teoría del foco guerrillero defendida por Ernesto Che Guevara y las ideas Mao Tse-Tung. El triunfo en Cuba impulsó a que desde la URSS se elaboraran nuevos conceptos

\footnotetext{
${ }^{8}$ Luis Corvalán, Los comunistas y el MIR, 15-121970, en http://www.socialismochileno.org/apsjb/1970/Corvalan\%20los\%20com unistas\%20y\%20el\%20Mirdic70.pdf, consultado en diciembre de 2014.
} 
como el de Estado Nacional Democrático, en el cual el liderazgo no debía corresponder al PC en particular, sino a las fuerzas progresistas de cada nación. Precisamente en esa etapa se fundó el Movimiento de Izquierda Revolucionaria (MIR) el 15 de agosto de 1965. Sus miembros salieron de varios grupos de izquierda: trotskistas, disidentes socialistas, maoístas, militantes expulsados del PC, anarcosindicalistas y cristianos de izquierda. El trostkista Enrique Sepúlveda fue su primer secretario general. ${ }^{9}$

Para la investigadora griega Eugenia Palieraki, los orígenes del MIR hay que buscarlos en el contexto de la historia de la izquierda chilena durante las décadas del veinte y del treinta del siglo pasado. Los políticos, dirigentes de izquierda y sindicalistas que se reunieron para formarlo servirían de puente entre aquella y la joven generación de los sesenta, núcleo que asumiría la dirección del movimiento.

[...] Sólo las trayectorias militantes y las motivaciones políticas de los fundadores del MIR pueden aportar respuestas, ya que -salvo algunas excepciones- habían sido militantes sindicalistas o de izquierda mucho tiempo antes de crear el movimiento. Por lo tanto, su acción política no dependió tanto de unas determinadas condiciones económicas y sociales como de un compromiso militante

\footnotetext{
${ }^{9}$ Eugenia Palieraki, "La opción por las armas. Nueva izquierda revolucionaria y violencia política en Chile (19651970)", Polis, 19, 2008, Publicado el 23 julio 2008, http://polis.revues.org/3882, consultado diciembre de 2014.
}

personal o generacional de larga data $[\ldots]^{10}$

Como hemos analizado Luis Reinoso, expulsado del PC por promover la lucha armada, había desarrollado una visión crítica con respecto a las relaciones entre ese Partido y la URSS, al tiempo que simpatizaba con los principios de la Revolución China y la teoría maoísta de las "dos piernas", que le otorgaba un rol esencial a los campesinos como fuerza revolucionaria. Algunos de sus seguidores contribuyeron a la formación de un pequeño aparato militar y fomentaron sus ideas dentro del MIR.

También Clotario Blest, el experimentado líder sindicalista, se unió al MIR y tras una visita a Cuba, invitado por el Comandante Guevara, radicalizó su posición. Él provenía de la corriente del cristianismo social. Pensaba que la moral constituía un elemento central de la identidad de la izquierda, tenía desconfianza en los partidos y era partidario de la unidad de todos los revolucionarios, la acción directa y la insurrección de los trabajadores de las ciudades. $^{11}$

Un grupo de jóvenes hizo suyas aquellas ideas. Dentro de ellos Miguel Enríquez y sus partidarios, a quienes había impactado mucho la experiencia cubana. Antes habían pertenecido al Partido Socialista y a Vanguardia Revolucionaria Marxista. Después del Segundo Congreso del MIR realizado en 1967, los trotskistas abandonaron o fueron expulsados de la organización. Entonces estos muchachos ganaron

\footnotetext{
${ }^{10}$ Eugenia Palieraki, ;La revolución ya viene! El MIR chileno en los años 1960, Santiago, LOM Ediciones, 2014, p.11.

${ }^{11}$ Ibídem.
} 
posiciones y Enríquez asumió su secretaría general.

Paralelamente, la falta de apoyo del Partido Comunista Boliviano a la guerrilla del Che y el respaldo del $\mathrm{PCCH}$ a la invasión soviética a Checoslovaquia provocó un gran desencanto entre muchos jóvenes militantes chilenos y un parte de ellos se unió al Movimiento.

En definitiva, desde su fundación las relaciones entre el MIR y el PCCH fueron muy conflictivas. El MIR había intentado, en un primer momento, acercarse al Partido, pero ante su desconfianza hacia los miristas, cambió de posición, y comenzó un proceso de críticas recíprocas. En criterios de Palieraki:

[...] la transición de un comunista al MIR podía ser interpretada por el militante como una ruptura violenta de su trayectoria, lo que no era el caso de los democratacristianos o de los católicos. La adhesión a la Democracia Cristiana o la pertenencia a una organización juvenil católica estaba, ante todo, motivada por consideraciones éticas. En cambio, la adhesión al Partido Comunista comportaba una sólida formación teórica marxista y la adhesión a unos principios ideológicos concretos. Por lo tanto, la transición a otro partido de izquierda que tenía desacuerdos teóricos con el PC podía ser visto como una ruptura radical con la militancia comunista. La segunda razón era la tradición política familiar. La DC era un partido relativamente nuevo $\mathrm{y}$, por consiguiente, carecía de fidelidades partidistas intergeneracionales. Los jóvenes militantes comunistas, en cambio, provenían con frecuencia de familias de larga tradición partidista, familias con dos o tres generaciones de militantes del PC. Por tanto, el peso de la tradición familiar es un factor a tener en cuenta para explicar por qué apenas hubo jóvenes militantes del PC que eligieran al MIR como opción. ${ }^{12}$

Ambas organizaciones compitieron en la búsqueda de nuevas afiliaciones entre la juventud Sus programas se excluían mutuamente, por lo que si un militante se decidía por el PC o por el MIR, ello implicaba rechazar al otro. Con la entrada de nuevos militantes, la dirección pasó a manos de Miguel Enríquez. Y es importante destacar como la influencia de los cristianos se fue haciendo mayor, cuando un grupo de jóvenes de la DC se incorporó al Movimiento. ${ }^{13}$

Durante las sesiones de su XIV Congreso, el PCCH buscó la unidad entre obreros, campesinos, capas medias, pequeños y medianos productores y en un Manifiesto al Pueblo consideró que dentro del Partido Radical y la DC también podían encontrarse sectores populares. En consecuencia ayudó a fundar la Unidad Popular (UP), en la cual también tomaron parte socialistas, radicales, social-demócratas, ibañistas, demócratas-cristianos y miembros del Movimiento de Acción Popular Unitaria. Con un programa de gobierno antimperialista y antioligárquico, la Unidad Popular declaró su candidato presidencial al socialista Salvador Allende.

En tanto el MIR realizaba sus primeras acciones armadas en junio de 1969 al asaltar varios bancos. Luego de algunas polémicas sobre la pertinencia de una guerrilla rural, Movimiento focalizó

\footnotetext{
${ }^{12}$ Ibídem, pp. 221.

${ }^{13}$ Ibídem.
} 
sus combates en el sector urbano, con poca influencia entre el campesinado $\mathrm{y}$ los obreros.

Según Pascal Allende, quien fuera posteriormente secretario general del MIR y por revelaciones de la hija de Salvador Allende, en plena campaña presidencial el candidato de la UP realizó una reunión secreta con Miguel Enríquez. Este le explicó que el MIR había dejado en libertad a sus militantes para que decidieran votar o no por su candidatura $\mathrm{y}$ que estaba preocupado por su seguridad. Salvador le pidió que detuvieran las acciones armadas para no perjudicar su campaña y aceptó que militantes miristas formaran el Grupo de Amigos Personales para que lo protegieran. $^{14}$

El triunfo de la Unidad Popular en septiembre de 1970 constituyó la plasmación de la política del PCCh. Por primera vez, una coalición de izquierda gobernaba ciertamente, aunque no tenía todo el poder. Sus medidas más importantes fueron la nacionalización de ramas básicas de la economía, la expropiación de los monopolios y la banca, la liquidación del latifundio, la implementación de la Reforma Agraria, la atención a los reclamos de los trabajadores, el mejoramiento de las condiciones de las condiciones de vida de los sectores más pobres.

Con el ascenso de Salvador Allende a la silla presidencial, el MIR suspendió sus operaciones armadas, abandonó la clandestinidad y trató de insertarse a la vida política a través de los Frentes Intermedios de Masas. Además colocó su estructura militar a disposición

14 Andrés Pascal Allende, "El MIR y Allende", Punto Final, n. 665, 26 de junio de 2008 en http://www.puntofinal.cl/665/mir.phpPunto final, edición 665 (26 de junio-10 de julio 2008) de su seguridad. Pocas semanas después de haber asumido, se produjo un altercado entre el MIR y el PC en la ciudad de Concepción, durante el cual murió un mirista. El Presidente intervino personalmente exigiendo a la dirección del Partido que dialogara con el Movimiento para impedir nuevas pugnas. Ante esa situación, el secretario General del PC Luis Corvalán declaró públicamente el 15 de diciembre de 1970 que el MIR tenía una concepción completamente diferente a los comunistas sobre las formas de lucha revolucionaria, sin embargo había comprendido el rumbo que debía seguir la revolución chilena y estaba apoyando al Gobierno Popular. Por lo tanto, creía que se iba a dar "una suerte de entendimiento" entre ambas organizaciones, aunque subsistían diferencias en muchos aspectos y la lucha ideológica continuaría en un plano más fraternal. ${ }^{15}$

A finales de ese año, se produjo una amnistía presidencial para los miembros del MIR y posteriormente se le ofreció a Miguel Enríquez que ocupara la cartera de Ministro de Salud, quien no aceptó alegando que no creía posible llevar a vías de hecho los cambios revolucionarios a que aspiraba, por medios institucionales. ${ }^{16}$

Los partidarios de la Unidad Popular, que en el momento en que Allende fue elegido eran poco más de un tercio de la sociedad chilena, fueron aumentando su volumen hasta llegar al $43,85 \%$ en las elecciones parlamentarias

\footnotetext{
${ }^{15}$ Luis Corvalán, Los comunistas y el MIR, 15-121970, en http://www.socialismochileno.org/apsjb/1970/Corvalan\%201os\%20com unistas $\% 20 \mathrm{y} \% 20 \mathrm{el} \% 20 \mathrm{Mirdic} 70 . \mathrm{pdf}$, consultado en diciembre de 2014.

${ }^{16}$ Pascal Allende, obra citada.
} 
de 1973; sin embargo, la oposición (la Democracia Cristiana y el Partido Nacional) unieron sus fuerzas formando la Confederación de la Democracia (CODE), que aumentó la polarización del país.

En mayo de 1972 se realizaron varias conversaciones entre el MIR y la UP, que fueron ineficaces, según criterio de Pascal Allende. Posteriormente, en el mes de julio, el MIR y todos los partidos de la Unidad Popular, con la excepción del Comunista, convocaron a una asamblea popular en Concepción, y ello provocó el crecimiento de las tensiones con el Presidente.

El 5 de agosto la policía de Investigaciones -que estaba encabezada por dirigentes comunistas y socialistas partidarios de reprimir al MIR- allanó el campamento Lo Hermida -donde la influencia mirista era muy fuerte- y dispararon sobre los pobladores que se resistieron a la incursión policial, matando e hiriendo a varios de ellos. El MIR advirtió al gobierno que si no detenía la ofensiva represiva usaría las armas de que disponía para defenderse. Una vez más, el presidente Allende intervino para evitar el conflicto $[\ldots]^{17}$

Por otra parte, la derecha antigubernamental iba tomando fuerzas y en octubre de 1971 realizó un paro patronal. Los medios imperialistas estaban dando apoyo a la oposición más reaccionaria y particularmente a sus elementos dentro de las Fuerzas Armadas. Cuando en junio de 1973 se produjo el intento de levantamiento militar -cuenta Pascal Allende- "las banderas rojinegras del MIR ondearon junto a la bandera chilena y las banderas

\footnotetext{
${ }^{17}$ Pascal Allende, obra citada.
}

de los partidos de toda la Izquierda, cuando miles de hombres y mujeres del pueblo rodearon el palacio de La Moneda para defender al compañero presidente y exigir castigo a los golpistas." Pero,

[...] ni el MIR se decidió a repartir las armas al pueblo [...] por temor a provocar un enfrentamiento con el gobierno y dividir el movimiento popular, ni el gobierno aprovechó esta victoria para intervenir dentro de las FF.AA (...) A partir de entonces, el inmovilismo del conjunto de la Izquierda y del gobierno creció, junto con la desmoralización y el temor, en el movimiento de masas. ${ }^{18}$

Aunque el presidente Allende intentó una salida política institucional, convocando a un plebiscito, ya el golpe era imparable. La mañana del 11 de septiembre, Miguel Enríquez y Allende se comunicaron por última vez. Miguel le ofreció el apoyo de combatientes del MIR para proteger su salida de La Moneda y continuar la resistencia en los barrios populares. Allende no aceptó y le mandó a decir: "Yo no me muevo de aquí, cumpliré hasta mi muerte la responsabilidad que el pueblo me ha entregado. Ahora es tu turno, Miguel..."19

Los propósitos del Partido Comunista al involucrarse en el proyecto de la Unidad Popular no estaba tratando de iniciar una lucha por el socialismo, sino de conseguir objetivos antimonopolistas, antilatifundistas y antiimperialistas por medios colaboracionistas, incluso con la Democracia Cristiana. Mientras que el MIR, que reconocía teóricamente la necesidad de atracción de las clases

\footnotetext{
${ }^{18}$ Ibídem.

${ }^{19}$ Ibídem
} 
medias, en la práctica no se mostró dispuesto a hacer concesiones para conseguirlo: su proyecto de alianzas era esencialmente entre obreros y campesinos con las capas pobres del campo y la ciudad. Así pues, el PCCh y el MIR fueron las dos organizaciones que más claramente muestran su desacuerdo sobre la concepción del poder popular y los dos proyectos de la izquierda más contrapuestos. $^{20}$

Los Cordones Industriales -nos analiza Luis Corvalán- surgieron, por iniciativa del MIR y de un sector del Partido Socialista en 1973 y fueron proclamados como órganos de poder alternativo. El PC los objetó al comienzo. Después de varias conversaciones, socialistas y comunistas llegaron a la conclusión de la necesidad de apoyar dichos cordones, para darles el carácter proletario y que no órganos paralelos, ni opuestos a la Unidad Popular. El MIR que fue uno de las organizaciones más activas dentro de los Cordones, sin embargo tenía una visión totalmente diferente, pues los consideraba un poder autónomo e independiente, en lucha contra el Estado burgués y sus instituciones. Por eso su línea de orientación era construir un poder dual que abriera paso a un Estado proletario. ${ }^{21}$

Según el criterio del estudioso francés Franck Gaudichaud, en busca de la moderación para aplicar el programa de la Unidad Popular, el Partido Comunista desempeñó un papel esencial. Sus objetivos eran garantizar la estabilidad del Gobierno y no asustar "a la burguesía nacional”. Y a la larga,

\footnotetext{
${ }^{20}$ Jesús Sánchez Rodríguez, Reflexiones sobre la revolución chilena, en http://www.rebelion.org/docs/52569.pdf, consultado en diciembre de 2014.

${ }^{21}$ Ibídem.
}

impuso una hegemonía sobre el gobierno con el lema "Consolidar para avanzar". Es por eso que Orlando Millas, ministro comunista, llamó a devolver las industrias ocupadas por sus obreros y el PC frenó la constitución del "poder popular" (en particular los Cordones Industriales). Mientras que la posición del MIR fue más radical: entregando un apoyo crítico al gobierno y pronunciándose por un "poder popular alternativo" al Estado burgués. El Frente de Trabajadores Revolucionarios (tendencia sindical del MIR), criticó el "control burocrático" de la UP sobre el movimiento obrero.

Pero la mayoría de este sector político continuó dependiente de las iniciativas gubernamentales y no logro ocupar un espacio político copado por los dos grandes partidos del movimiento obrero (el PC y el PS). Además, el MIR chileno adopto en algunas ocasiones posicionamientos infantiles, producto de su desesperación por tratar de tener más influencia en una clase obrera que tenía depositadas mayoritariamente sus esperanzas en el gobierno. ${ }^{22}$

$\mathrm{Si}$ bien es cierto que el gobierno Allende no capituló ante la reacción, ocurrió otra de las posibilidades previstas por el MIR, el golpe de Estado, que encontró a la izquierda dividida y desorganizada, por lo cual no pudo emprender una resistencia popular masiva. En esas circunstancias y consecuente con sus principios, el MIR decidió que sus miembros no debían

\footnotetext{
${ }^{22}$ Franck Gaudichaud, "Pensar las alternativas yel socialismo en la América latina del siglo XXI", en

http://www.nodo50.org/cubasigloXXI/congreso0 4/gaudichaud_290204.pdf, consultado el 9 de febrero de 2015, p. 6.
} 
asilarse, sino presentar una batalla frontal contra la dictadura pinochetista.

Como hemos señalado, tanto el Partido Comunista como el MIR fueron actores políticos importantes durante el período de la Unidad Popular. Fatalmente, siendo ambas organizaciones de la izquierda política, no pudieron concertar un compromiso de lucha común, pues primaron por encima de todo las divergencias de tipo estratégicotáctica que cada una enarbolaba. El costo político de esta situación fue altísimo. La reacción arremetió contra el pueblo chileno y, en especial, contra sus organizaciones representativas. Los partidos tuvieron que pasar a la clandestinidad, miles de sus integrantes fueron asesinados, torturados, encarcelados o tuvieron que salir del país y se instauró una tiranía, cuyas secuelas aún pueden verse en la sociedad chilena.

Este texto forma parte del libro de Rosario Alfonso Parodi y Fernado Luis Rojas López (comp.), Ahora es tu turno Miguel. Un homenaje cubano a Miguel Enríquez, Instituto Cubano de Investigación Cultura Juan Marinello, La Habana, 2015, pp. 77-86 